\title{
Recent Advances in Indentation Techniques and Their Application to Mechanical Characterization
}

\author{
Takahito Ohmura ${ }^{1,2,3, *}$ \\ ${ }^{1}$ National Institute for Materials Science, Tsukuba 305-0047, Japan \\ ${ }^{2}$ Course of Advanced Nanomaterials Science and Engineering, Kyushu University, Fukuoka 819-0395, Japan \\ ${ }^{3}$ Elements Strategy Initiative for Structural Materials, Kyoto University, Kyoto 606-8501, Japan
}

\begin{abstract}
This paper presents the current research trends in indentation techniques, especially on the micro- and nanoscales, and the application of such techniques for the mechanical characterization of various materials. The survey was carried out based on the special issue of Materials Transactions (Vol. 60, No. 8), published in August 2019. The indentation techniques have diversified, and they have been implemented in instrumentation specialized for in situ measurements, environmental control including elevated temperatures, and mechanical property evaluation of soft materials. These techniques can also be applied in a more fundamental manner to assist the physical modeling of plastic deformation and fracture. For each of the various topics, a brief introduction is given to the cutting-edge methods and novel approaches in characterization that offer opportunities for innovative developments in materials science. [doi:10.2320/matertrans.MT-M2020371]
\end{abstract}

(Received December 3, 2020; Accepted January 8, 2021; Published February 19, 2021)

Keywords: indentation-induced deformation, elasticity, plasticity, fracture, continuum mechanics, dislocation theory, microstructure

\section{Introduction}

Indentation testing was first adopted for engineering applications more than 100 years ago, and hardness testing was given a theoretical foundation in the elegant equation $H=3 \sigma_{\mathrm{y}}$ by Tabor in 1951. Since then, indentation techniques have been used as simple tools to evaluate the mechanical properties of metallic materials, and developments are still being made in instrumentation and applications to various materials. Nanoindentation is one of the most rapidly developing techniques with a large demand for application in the characterization of nanomaterials, including thin films/ coatings. The nanoindentation technique is approaching the milestone of the 30-year anniversary of the publication of the landmark paper by Oliver and Pharr in 1992, which formed the basis of ISO14577 in 2002. Instrumented indentation techniques are already recognized as some of the most useful and powerful tools for testing materials. As material design technology advances into ever smaller scales, finer microstructures, and multielement structures, there would be a strong demand for further evolution of these techniques in order to achieve higher performance even in harsh environments, for example, at elevated temperatures. In addition to industrial engineering applications, indentation techniques have been used in fundamental science, including atomicscale modeling of the elemental steps of deformation and fracture. The pop-in phenomenon at the point of plasticity initiation under stress is a typical example of a quantum theoretical behavior commonly investigated by indentation techniques. The indentation technique is no longer a mere hardness testing method but a cutting-edge approach in the expanding fields of mechanics, physics, chemistry, and materials science. This paper presents the current research trends in indentation-related topics.

${ }^{*}$ Corresponding author, E-mail: ohmura.takahito@nims.go.jp

\section{The Publication Trend and the Cutting-edge Activ- ities}

The conference series of the International Indentation Workshop (IIW) is one of the major networking events in the indentation community and was launched in 1996 in Cambridge, UK. The sixth event, IIW6, was held in July 2018 in Sapporo for the purpose of reviewing the present state of the art of indentation techniques. Many excellent papers were presented, and some of them were published in August 2019 in a special issue of Materials Transactions (Vol. 60, 8) under the title "Recent Advances in Indentation Techniques". 1) The special issue contains nine selected articles, including a review paper by a keynote speaker, distinguished papers by poster by young scientists, and contributed papers mostly by participants in the workshop.

The special issue covers new methodologies of in situ indentation testing with various observation methods, including transparent optical microscopy, ${ }^{2)}$ photoelastic evaluation, ${ }^{3)}$ Raman spectroscopy, ${ }^{4,5)}$ and macroscopic 2D observation with a wedge indenter. ${ }^{6,7)}$ Other topics include elasticity modeling for conical and pyramidal indenters, ${ }^{8)}$ evaluation of the conventional yield stress and field, ${ }^{9)}$ and measurements in harsh environments e.g., at elevated temperatures. ${ }^{10)}$

The historical trend in the indentation field is briefly reviewed prior to describing the contents in the special issue. Research activities in the indentation field have been increasing, especially during the last two decades. Figure 1 shows the trend of the decennial number of publications with the keywords including "indentation" since around 1900. The total number was less than 50 for the half century before 1950, approached 100 in the subsequent decade, and grew fourfold in the subsequent decade. The large increase in the 1960s may have been enabled by the mathematical formulation of Tabor published in "Hardness of Metals" in 1951. ${ }^{11)} \mathrm{He}$ established the equation $H=3 \sigma_{\mathrm{y}}$, where $H$ is the indentation hardness and $\sigma_{\mathrm{y}}$ is the yield stress in tensile 


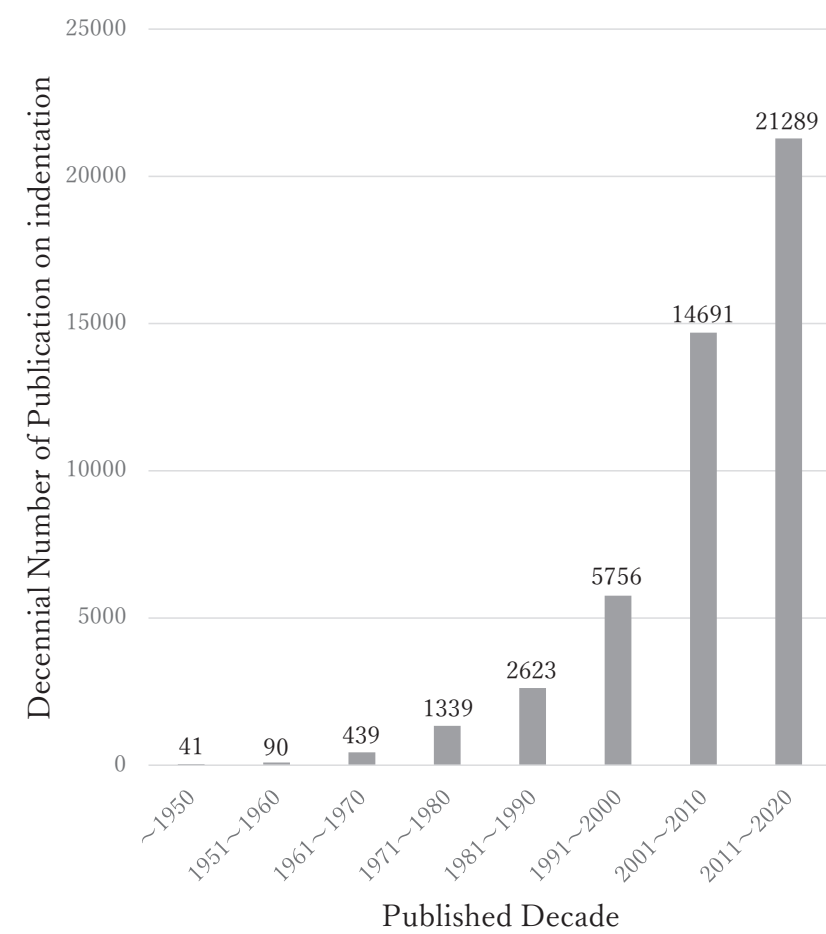

Fig. 1 Trend of the decennial number of publications on indentationrelated research since around 1900. (Data were used from Scopus on Nov. 2020).

testing. The establishment of this relationship activated the academic field and led to a significant expansion in industrial applications of indentation techniques. The next increase in publications related to indentation occurred in the 1990s, triggered by the great innovations in nanoindentation apparatuses with the capability of continuous load-displacement measurements ${ }^{12)}$ and an analytical approach for the evaluation of the elastic modulus and plastic hardness by Oliver and Pharr (the O-P method). ${ }^{13}$ ) These authors also proposed a method to calibrate a truncation of an indenter tip with "Area Function Method", which was a welcome solution for the most serious problem in nanoscale measurements. Additionally, the universal applicability of the O-P method facilitated standardization of the analytical protocol for property estimation, leading to the establishment of ISO 14570 in 2002. ${ }^{14)}$ After the standardization, there was an explosive increase in the number of publications in the 2000s and 2010s.

The history of the field proves that new methodology can fuel great advances, and that the innovations presented in the special issue may therefore be of great interest to the indentation community.

One of the most important bottlenecks in indentation techniques is accurate estimation of the contact (projected) area between the indenter and the sample, which is imperative for calculating the hardness. To address this critical issue, Mineta et al. ${ }^{2)}$ proposed a new method, in situ contact area measurement, for application to metallic materials using an optically transparent indenter with an immersion liquid. They demonstrated that the shape of the contact area under the loading and unloading conditions is not symmetrical owing to the anisotropic plasticity behavior of $\mathrm{Mg}$ alloys. Figure 2 shows in situ optical microscope images during the loading segment of an analysis of pure $\mathrm{Mg}$. The edge of the indent mark displays broken lines, and the shape of the mark is distorted even though the indenter is spherical. The image includes not only a slip line but also twinning on the sample surface. A similar analysis of a TiNi superelastic alloy revealed a martensitic transformation during loading, and the reverse transformation was observed during unloading. These results can be obtained only by the new method, and further applications are expected to be useful for various materials, including soft materials and brittle properties.

Understanding the elastic deformation behavior has been a focus of indentation-induced deformation analysis since the early the 1900s. Visualization of the elastic stress/strain field underneath the indenter is a very attractive but difficult challenge. Asai et al. ${ }^{3)}$ presented an advanced technique to show a three-dimensional stress map through microphotoelastic measurements using a spherical indenter applied to silica and soda-lime glasses. Figure 3 shows the principle stress map of (a) silica glass and (b) soda-lime glass under the spherical indenter. They demonstrated that tensile stress in the radial direction is generated during loading for both glasses, but that the stress distributions are different. They proposed that the difference in the stress field was due to a difference in the mechanism of plastic deformation in the two materials, governed by densification in silica and by shear flow in soda-lime glass. This technique is a powerful tool to investigate the elastic deformation behavior in various materials, including organic materials that are more attractive than ever as a target of indentation study.

The mechanisms of non-elastic behavior under certain load conditions have attracted interest since the concept of indentation plastic hardness was established in the early 1900s. Spectroscopy and/or microscopy with in situ straining play an essential role in revealing and understanding the dynamic behavior of materials. Raman spectroscopy in situ indentation techniques have been demonstrated by Yoshida et $a l .{ }^{4)}$ and Maslenikov et al. ${ }^{5)}$ Yoshida et al. presented in situ Raman spectra of silica glass under a Vickers indenter (a) during loading and (b) unloading, as illustrated in Fig. 4. They found that the in situ Raman spectra of silica glass under a Vickers indenter show remarkable peak broadening, suggesting a wider bond angle distribution, which is never observed in hydrostatic compression. The intensity of the main peak at $450 \mathrm{~cm}^{-1}$ decreased after unloading, indicating volume shrinkage or permanent densification. This indicated a significant effect of contact deformation and damage caused by shearinduced structural change. Maslenikov et al. demonstrated the existence of structural phases in silicon depending on the applied load. Silicon is an attractive material for indentationinduced phase transformation owing to its unique mechanical and electrical properties. ${ }^{15)}$

Two-dimensional wedge indentation is another suitable mode of deformation for an in situ approach because a crosssectional view is available for both the indenter and the material being analyzed. Sugihara et al. ${ }^{6}$ applied this technique to aluminum for analyzing the material flow phenomena in the vicinity of the contact region between the 


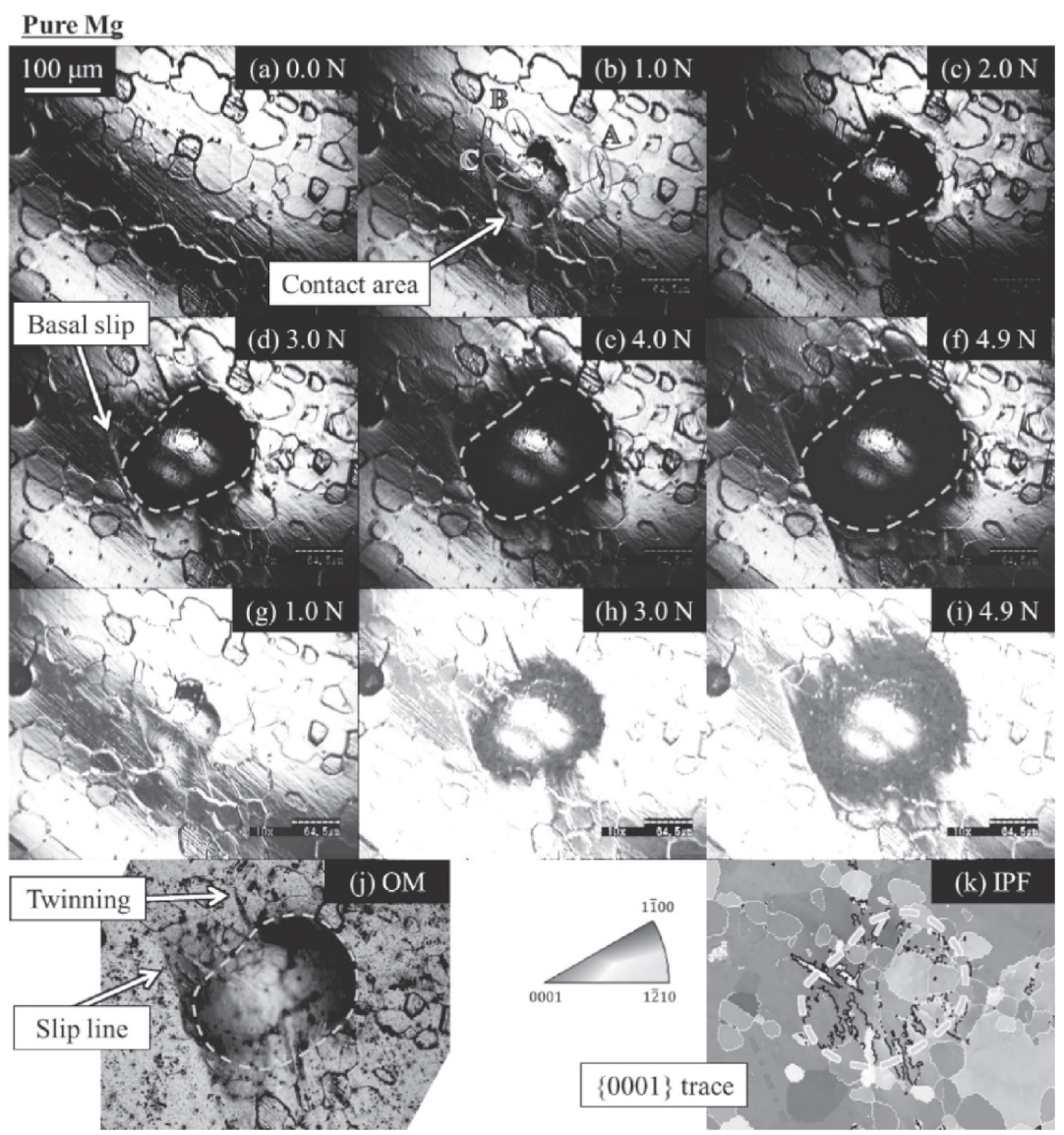

Fig. 2 In-situ optical microscope images during loading segment for Mg alloy. See details in Ref. 2).

(a)

Loading $0.5 \mathrm{~N}$

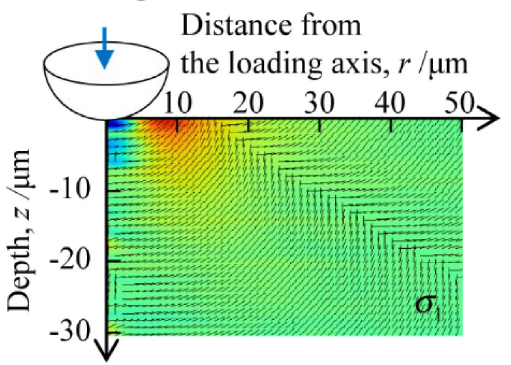

(b)

Loading $0.5 \mathrm{~N}$

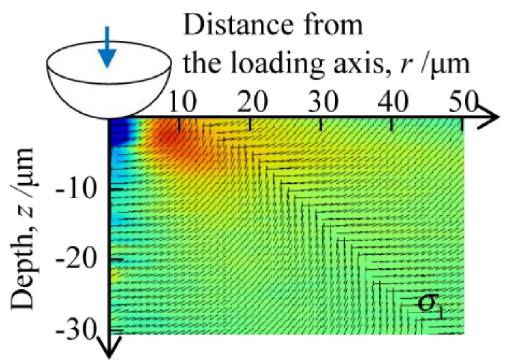

Unloading $0.5 \mathrm{~N}$

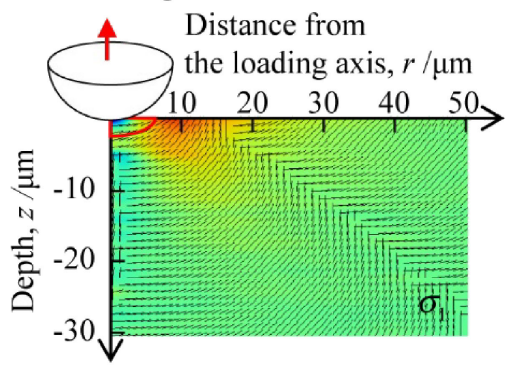

Unloading $0.5 \mathrm{~N}$

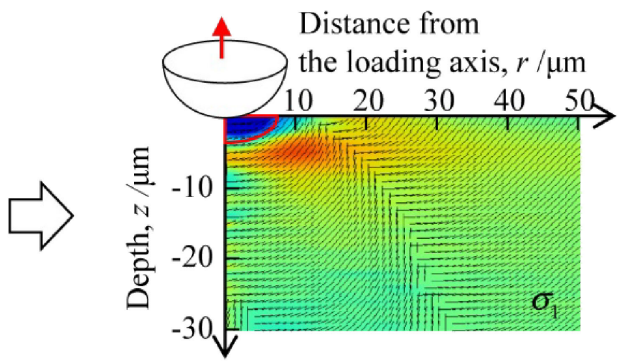

$-300$

$350 / \mathrm{MPa}$

Fine black lines: Trajectories of principal directions

Fig. 3 Principle stress map of (a) silica glass and (b) soda-lime glass under the spherical indenter. See details in Ref. 3). 

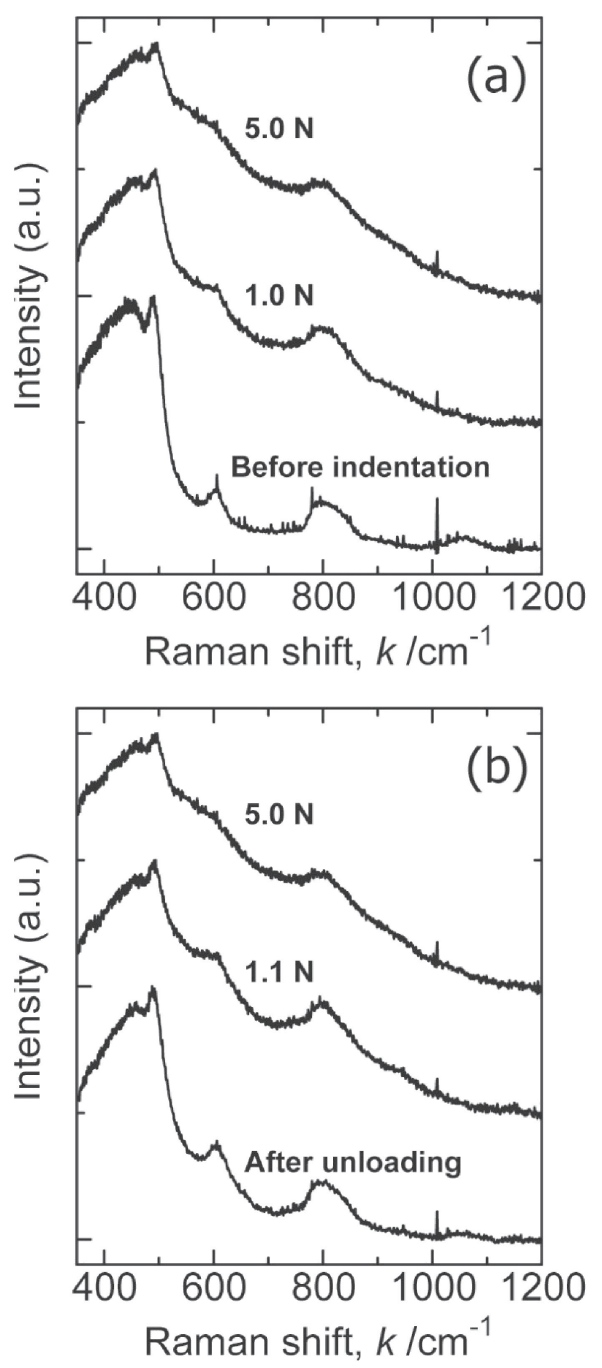

Fig. 4 In-situ Raman spectra of silica glass under a Vickers indenter for (a) during loading and (b) unloading. See details in Ref. 4).

indenter and the sample at various indenter angles and under various lubrication conditions. Figure 5 shows the strain field underneath indenters of various angles. The strain and viscosity depend on the indenter angle and on the friction interaction at the indenter-material interface, respectively. Udupa et $a l^{7)}$ showed the evolution of the plastic strain field under a wedge indenter using an in situ image correlation technique. They distinguished two deformation modes: a cutting mode with a narrow angle indenter, and a radialcompression mode with a wide-angle wedge indenter. They found a significant difference in the metal flow parallel and perpendicular to the indenter face when comparing the cutting and radial-compression modes.

Other topics in the special issue include fundamental, conventional, and challenging approaches. Chaudhri ${ }^{8)}$ reviewed a formulation in an elastic contact of a rigid cone on an elastic half-space. The discussion was initiated based on the Love equation, and he pointed out the three major arguments in the model. First, he found that the Love equation matched well with experimental results obtained using a conical indenter with the range of apex angle varying from $90^{\circ}$ to $136^{\circ}$. Second, he found that in the case of a conical indenter, the load-depth relation follows a monomial

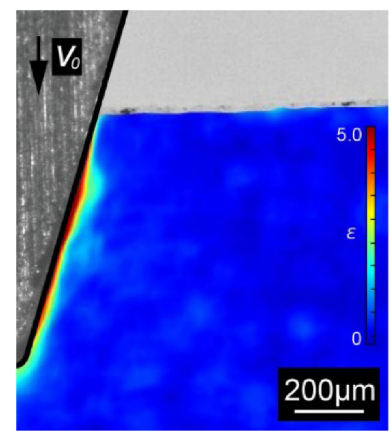

( a ) $\alpha_{0}=30^{\circ}$

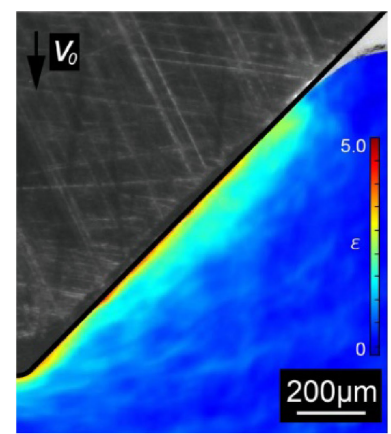

( c ) $\alpha_{0}=90^{\circ}$

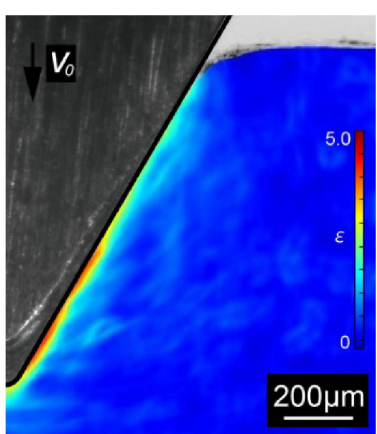

( b ) $\alpha_{0}=60^{\circ}$

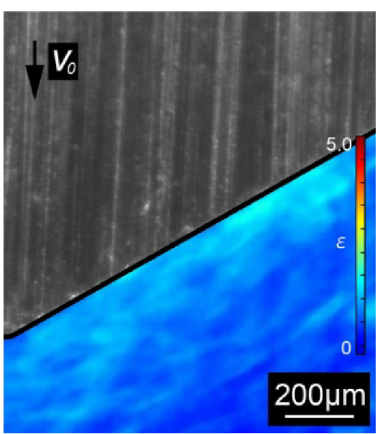

( d ) $\alpha_{0}=120^{\circ}$
Fig. 5 Strain field underneath indenters with various indenter angles. See details in Ref. 6).

function, while in the case of a pyramidal indenter, the loaddepth relation fits with a polynomial. Third, he found that the normal direction of the load component was found to be limited to the sample surface within the region of contact between the indenter and the sample, while the horizontal direction of the load component also included the region outside of the contact area. These findings are important and useful for analyzing an indentation-induced elastic deformation. Yield stress evaluation by an indentation approach has been a major engineering issue since its establishment by Tabor. ${ }^{11)}$ Pero et al. ${ }^{9)}$ showed a distribution of nanohardness in the cross-sectional field over a larger indentation plastic zone by a dual scale indentation test. They identified the transition boundary between the hemispherical strain-hardened region and the surrounding elastic region, and discussed the yield stress evaluation based on cavity models. Nanoindentation measurements in harsh environments are a challenging task. Ruzic et al. ${ }^{10)}$ demonstrated an elevated temperature measurement up to $1073 \mathrm{~K}$ with a $3 \mathrm{mN}$ peak load for nickel-based superalloys. Figure 6 shows (a) typical load-displacement curves at various temperatures and (b) the temperature dependence of the elastic modulus and hardness. The curves show a reasonable temperature dependence of both the hardness and Young's modulus, indicating that the measurements were performed with a good sequential protocol.

\section{Other Global Trends}

The overall trends in indentation techniques in the past two decades should be also reviewed briefly. They may be categorized into three fields: analytical protocol of load-depth data, fundamental physical modeling of deformation, and 


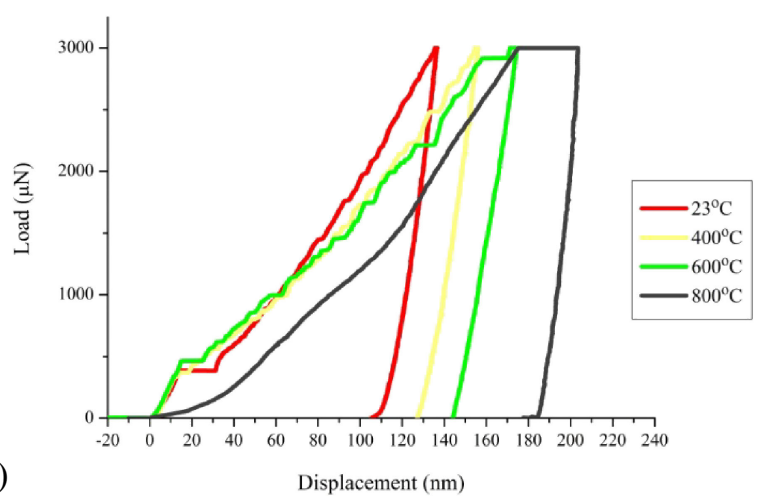

(a)

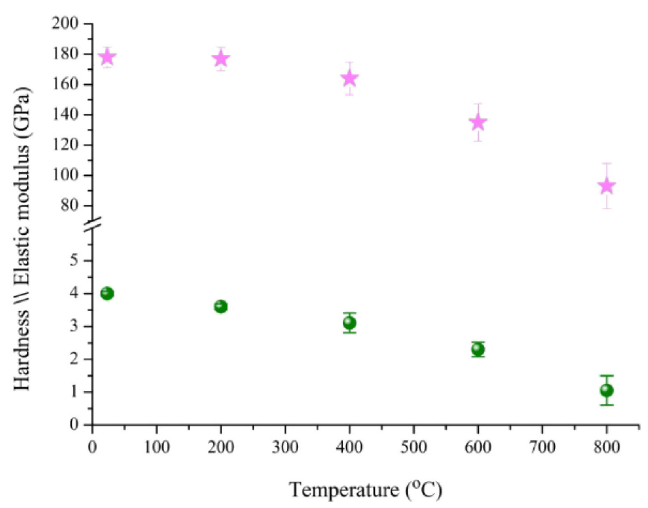

(b)

Fig. 6 (a) Typical load-displacement curves at various temperatures and (b) the temperature dependence of elastic modulus and hardness for Ni-base superalloy. See details in Ref. 10).

application to various materials. The methodology includes analysis and interpretation of load-depth data ${ }^{16-25}$ and new methods and instrumentation. ${ }^{26-30)}$ Despite the establishment of the ISO standard and availability of commercial testing equipment, the technology continues to evolve. Indentation is utilized for not only property evaluation but also for analyzing the fundamental deformation mechanisms. Interesting areas of inquiry are plasticity initiation, ${ }^{31-38)}$ deformation mechanisms, fracture and size effect, ${ }^{39-50}$ ) microstructural evolution, phase transformation and twin formation, ${ }^{51-58)}$ creep behavior, ${ }^{59-62)}$ and simulation and modeling. ${ }^{63-66)}$ The application of indentation technique is still being expanded to encompass new materials such as nano/micro-materials, including graphene, ${ }^{67-69)}$ carbon nanotubes, ${ }^{70-73)}$ nanostructured materials (including nanoporous materials), ${ }^{74-80)}$ thin films and coatings, ${ }^{81-93)}$ ionirradiated surface layer, ${ }^{94-98)}$ fine structures and ultra-finegrained materials, ${ }^{99-113)}$ bulk metallic glass, ${ }^{114-123)}$ highentropy alloys, ${ }^{124,125)}$ spark plasma sintered ${ }^{126-133)}$ and additive manufactured materials, ${ }^{134-137)}$ polymers, soft materials, ${ }^{138-148)}$ bio materials and viruses, ${ }^{149-158)}$ cement and concrete, ${ }^{159-164)}$ and others. ${ }^{165-167)}$

\section{Summary}

The technology of indentation analysis is evolving and expanding to improve methodology and to permit its application to various new materials. The technique has been generalized to evaluate the mechanical properties of hardness and Young's modulus based on standardized protocols in an empirical approach, while it has also been used to investigate the deformation behavior in a more fundamental physical framework. The new trends in the field have been discussed frequently by the world leaders in indentation in recurring international workshops such as the International Indentation Workshop (IIW), which was launched in 1996 and has its 7th event scheduled for 2021 in Slovakia. Improvement of indentation analysis and the broadening of its applications is still ongoing, and innovative approaches are expected to be utilized for the further advancement of materials science into the future.

\section{REFERENCES}

1) T. Ohmura and N. Sekido: Mater. Trans. 60 (2019) 1403.

2) T. Mineta, S. Miura, K. Oka and T. Miyajima: Mater. Trans. 60 (2019) 1416-1422.

3) K. Asai, S. Yoshida, A. Yamada, J. Matsuoka, A. Errapart and C.R. Kurkjian: Mater. Trans. 60 (2019) 1423-1427.

4) S. Yoshida, T.H. Nguyen, A. Yamada and J. Matsuoka: Mater. Trans. 60 (2019) 1428-1432.

5) I.I. Maslenikov, V.N. Reshetov and A.S. Useinov: Mater. Trans. 60 (2019) 1433-1435.

6) T. Sugihara, A. Udupa and K. Viswanathan: Mater. Trans. 60 (2019) 1436-1441.

7) A. Udupa, N. Sundaram, T. Sugihara and S. Chandrasekar: Mater. Trans. 60 (2019) 1442-1449.

8) M.M. Chaudhri: Mater. Trans. 60 (2019) 1404-1410.

9) R. Pero, G. Maizza, F. De Marco, P. De Fazio, R. Montanari and T. Ohmura: Mater. Trans. 60 (2019) 1450-1456.

10) J. Ruzic, I. Watanabe, K. Goto and T. Ohmura: Mater. Trans. 60 (2019) 1411-1415.

11) D. Tabor: Hardness of Metals, (Clarendon Press, Oxford, 1951) p. 105.

12) D. Newey, M.A. Willkins and H.M. Pollock: J. Phys. E 15 (1982) 119-122.

13) W.C. Oliver and G.M. Pharr: J. Mater. Res. 7 (1992) 1564-1583.

14) ISO 14577: 2002.

15) T. Suzuki and T. Ohmura: Philos. Mag. A 74 (1996) 1073-1084.

16) X. Li and B. Bhushan: Mater. Charact. 48 (2002) 11-36.

17) A.C. Fischer-Cripps: Surf. Coat. Tech. 200 (2006) 4153-4165.

18) M. Sitti and R.S. Fearing: J. Adhes. Sci. Technol. 17 (2003) 10551073.

19) G.M. Pharr, E.G. Herbert and Y. Gao: Annu. Rev. Mater. Res. 40 (2010) 271-292.

20) M.D. Uchic and D.M. Dimiduk: Mater. Sci. Eng. A 400-401 (2005) 268-278.

21) G.M. Pharr and A. Bolshakov: J. Mater. Res. 17 (2002) 2660-2671.

22) A.C. Fischer-Cripps: Vacuum 58 (2000) 569-585.

23) W.C. Oliver and G.M. Pharr: J. Mater. Res. 19 (2004) 3-20.

24) J.-C. Kuo and I.-H. Huang: Mater. Trans. 51 (2010) 2104-2108.

25) N. Fujisawa, T. Ogura and A. Hirose: Mater. Trans. 57 (2016) 10061009.

26) A. Gouldstone, N. Chollacoop, M. Dao, J. Li, A.M. Minor and Y.-L. Shen: Acta Mater. 55 (2007) 4015-4039.

27) M.R. VanLandingham: J. Res. NIST 108 (2003) 249-265.

28) J.L. Bucaille, S. Stauss, E. Felder and J. Michler: Acta Mater. 51 (2003) 1663-1678.

29) K. Goto, I. Watanabe and T. Ohmura: Int. J. Plast. 116 (2019) 81-90.

30) T. Mineta, S. Miura, K. Oka and T. Miyajima: Mater. Trans. 59 (2018) 602-611.

31) J. Li, K.J. Van Vliet, T. Zhu, S. Yip and S. Suresh: Nature 418 (2002) 307-310.

32) A. Gouldstone, H.-J. Koh, K.-Y. Zeng, A.E. Giannakopoulos and S. Suresh: Acta Mater. 48 (2000) 2277-2295.

33) C.A. Schuh: Mater. Today 9 (2006) 32-40.

34) K.J. Van Vliet, J. Li, T. Zhu, S. Yip and S. Suresh: Phys. Rev. B 67 (2003) 104105.

35) A.M. Minor, S.A. Syed Asif, Z. Shan, E.A. Stach, E. Cyrankowski, T.J. Wyrobek and O.L. Warren: Nat. Mater. 5 (2006) 697-702. 
36) C.A. Schuh, J.K. Mason and A.C. Lund: Nat. Mater. 4 (2005) 617621.

37) D. Lorenz, A. Zeckzer, U. Hilpert, P. Grau, H. Johansen and H.S Leipner: Phys. Rev. B 67 (2003) 172101.

38) M. Yoshida, T. Sumomogi, T. Endo, H. Maeta and T. Kino: Mater. Trans. 48 (2007) 1-5.

39) X. Deng, N. Chawla, K.K. Chawla and M. Koopman: Acta Mater. 52 (2004) 4291-4303.

40) A.A. Elmustafa and D.S. Stone: J. Mech. Phys. Solids 51 (2003) $357-$ 381.

41) K. Durst, B. Backes and M. Göken: Scr. Mater. 52 (2005) 1093-1097.

42) H. Bei, S. Shim, E.P. George, M.K. Miller, E.G. Herbert and G.M. Pharr: Scr. Mater. 57 (2007) 397-400.

43) T. Chudoba and F. Richter: Surf. Coat. Tech. 148 (2001) 191-198.

44) J.R. Greer, W.C. Oliver and W.D. Nix: Acta Mater. 53 (2005) 18211830

45) Y.-T. Cheng and C.-M. Cheng: Mater. Sci. Eng. R 44 (2004) 91-149.

46) T. Ohmura, K. Tsuzaki and F. Yin: Mater. Trans. 46 (2005) 20262029 .

47) T. Ohmura, L. Zhang, K. Sekido and K. Tsuzaki: J. Mater. Res. 27 (2012) 1742-1749.

48) L. Zhang and T. Ohmura: Phys. Rev. Lett. 112 (2014) 145504.

49) J.-J. Kim, Y. Choi, S. Suresh and A.S. Argon: Science 295 (2002) $654-657$.

50) M. Tanaka, K. Higashida, H. Nakashima, H. Takagi and M. Fujiwara: Mater. Trans. 44 (2003) 681-684.

51) L. Lu, R. Schwaiger, Z.W. Shan, M. Dao, K. Lu and S. Suresh: Acta Mater. 53 (2005) 2169-2179.

52) M. Eriksson and S. Jacobson: Tribol. Int. 33 (2000) 817-827.

53) C.S. Ruiz-Vargas, H.L. Zhuang, P.Y. Huang, A.M. Van Der Zande, S. Garg, P.L. McEuen, D.A. Muller, R.G. Hennig and J. Park: Nano Lett. 11 (2011) 2259-2263.

54) W.-S. Lee and F.-J. Fong: Mater. Trans. 48 (2007) 2650-2658.

55) W.-S. Lee, T.-H. Chen, C.-F. Lin and C.-L. Wu: Mater. Trans. 52 (2011) 1868-1875.

56) W.-S. Lee, T.-H. Chen, C.-F. Lin and Y.-L. Chuang: Mater. Trans. 51 (2010) 2013-2018.

57) W.-S. Lee, T.-H. Chen, C.-F. Lin and S.-L. Chang: Mater. Trans. 51 (2010) 1173-1177.

58) W.-S. Lee and S.-L. Chang: Mater. Trans. 56 (2015) 726-732.

59) B. Wei, T. Zhang, W. Li, D. Xing, L. Zhang and Y. Wang: Mater. Trans. 46 (2005) 2959-2962.

60) H. Takagi, M. Dao and K. Fujiwara: Mater. Trans. 55 (2014) 275-284.

61) H. Takagi, M. Dao, M. Fujiwara and M. Otsuka: Mater. Trans. 47 (2006) 2006-2014.

62) M. Fujiwara, H. Takagi and K. Higashida: Mater. Trans. 60 (2019) 503-512.

63) F. Roters, P. Eisenlohr, L. Hantcherli, D.D. Tjahjanto, T.R. Bieler and D. Raabe: Acta Mater. 58 (2010) 1152-1211.

64) N. Zaafarani, D. Raabe, R.N. Singh, F. Roters and S. Zaefferer: Acta Mater. 54 (2006) 1863-1876.

65) E.T. Lilleodden, J.A. Zimmerman, S.M. Foiles and W.D. Nix: J. Mech. Phys. Solids 51 (2003) 901-920.

66) M. Dao, N. Chollacoop, K.J. Van Vliet, T.A. Venkatesh and S. Suresh: Acta Mater. 49 (2001) 3899-3918.

67) C. Lee, X. Wei, J.W. Kysar and J. Hone: Science 321 (2008) 385-388.

68) G.-H. Lee, R.C. Cooper, S.J. An, S. Lee, A. Van Der Zande, N Petrone, A.G. Hammerberg, C. Lee, B. Crawford, W. Oliver, J.W. Kysar and J. Hone: Science 340 (2013) 1073-1076.

69) L. Sorelli, G. Constantinides, F.-J. Ulm and F. Toutlemonde: Cement Concr. Res. 38 (2008) 1447-1456.

70) T. Liu, I.Y. Phang, L. Shen, S.Y. Chow and W.-D. Zhang: Macromolecules 37 (2004) 7214-7222.

71) S.-F. Wang, L. Shen, W.-D. Zhang and Y.-J. Tong: Biomacromolecules 6 (2005) 3067-3072.

72) Z. Xia, L. Riester, W.A. Curtin, H. Li, B.W. Sheldon, J. Liang, B. Chang and J.M. Xu: Acta Mater. 52 (2004) 931-944.

73) M.S. Konsta-Gdoutos, Z.S. Metaxa and S.P. Shah: Cement Concr. Compos. 32 (2010) 110-115.

74) L. Song, L. Ci, H. Lu, P.B. Sorokin, C. Jin, J. Ni, A.G. Kvashnin, D.G. Kvashnin, J. Lou, B.I. Yakobson and P.M. Ajayan: Nano Lett. 10
(2010) 3209-3215.

75) J. Biener, A.M. Hodge, J.R. Hayes, C.A. Volkert, L.A. Zepeda-Ruiz, A.V. Hamza and F.F. Abraham: Nano Lett. 6 (2006) 2379-2382.

76) W.J. Wright, R. Saha and W.D. Nix: Mater. Trans. 42 (2001) 642-649.

77) F.-J. Ulm, M. Vandamme, C. Bobko, J. Alberto Ortega, K. Tai and C. Ortiz: J. Am. Ceram. Soc. 90 (2007) 2677-2692.

78) A.M. Hodge, J. Biener, J.R. Hayes, P.M. Bythrow, C.A. Volkert and A.V. Hamza: Acta Mater. 55 (2007) 1343-1349.

79) H.C. Barshilia, N. Selvakumar, B. Deepthi and K.S. Rajam: Surf. Coat. Tech. 201 (2006) 2193-2201.

80) J. Biener, A.M. Hodge, A.V. Hamza, L.M. Hsiung and J.H. Satcher, Jr.: J. Appl. Phys. 97 (2005) 024301.

81) R. Saha and W.D. Nix: Acta Mater. 50 (2002) 23-38.

82) A. Hörling, L. Hultman, M. Odén, J. Sjölén and L. Karlsson: Surf. Coat. Tech. 191 (2005) 384-392.

83) B. Bhushan and X. Li: Int. Mater. Rev. 48 (2003) 125-164.

84) J.A. Thompson and T.W. Clyne: Acta Mater. 49 (2001) 1565-1575.

85) X. Chen and J.J. Vlassak: J. Mater. Res. 16 (2001) 2974-2982.

86) J.A. Curran and T.W. Clyne: Surf. Coat. Tech. 199 (2005) 168-176.

87) X. Li, B. Bhushan, K. Takashima, C.-W. Baek and Y.-K. Kim: Ultramicroscopy 97 (2003) 481-494.

88) C.A. Charitidis: Int. J. Refract. Met. Hard Mater. 28 (2010) 51-70.

89) Y.C. Chim, X.Z. Ding, X.T. Zeng and S. Zhang: Thin Solid Films 517 (2009) 4845-4849.

90) Y.T. Pei, D. Galvan and J.Th.M. De Hosson: Acta Mater. 53 (2005) 4505-4521.

91) S.J. Bull: J. Phys. D 38 (2005) R393-R413.

92) W.-S. Lee, T.-Y. Liu and T.-H. Chen: Mater. Trans. 50 (2009) 17681777.

93) M. Ohki, T. Ishibashi and J. Kinoshita: Mater. Trans. 47 (2006) 1170_ 1177.

94) E. Hasenhuetl, R. Kasada, Z. Zhang, K. Yabuuchi, Y.-J. Huang and A. Kimura: Mater. Trans. 58 (2017) 749-756.

95) C. Liu, N. Hashimoto, S. Ohnuki, M. Ando and K. Shiba: Mater. Trans. 54 (2013) 96-101.

96) E. Wakai, M. Ando, T. Sawai and S. Ohnuki: Mater. Trans. 48 (2007) 1427-1430.

97) E. Hasenhuetl, R. Kasada, Z. Zhang, K. Yabuuchi and A. Kimura: Mater. Trans. 58 (2017) 580-586.

98) S. Muraishi, H. Naito and T. Aizawa: Mater. Trans. 48 (2007) 1859_ 1863.

99) K.S. Kumar, S. Suresh, M.F. Chisholm, J.A. Horton and P. Wang: Acta Mater. 51 (2003) 387-405.

100) R. Schwaiger, B. Moser, M. Dao, N. Chollacoop and S. Suresh: Acta Mater. 51 (2003) 5159-5172.

101) G. Constantinides and F.-J. Ulm: J. Mech. Phys. Solids 55 (2007) 6490.

102) C.A. Schuh, T.G. Nieh and H. Iwasaki: Acta Mater. 51 (2003) 431443.

103) M. Jin, A.M. Minor, E.A. Stach and J.W. Morris, Jr.: Acta Mater. 52 (2004) 5381-5387.

104) Z.B. Wang, N.R. Tao, S. Li, W. Wang, G. Liu, J. Lu and K. Lu: Mater. Sci. Eng. A 352 (2003) 144-149.

105) T. Ohmura, K. Tsuzaki and S. Matsuoka: Scr. Mater. 45 (2001) 889894.

106) T. Ohmura, K. Tsuzaki and S. Matsuoka: Philos. Mag. A 82 (2002) 1903-1910.

107) T. Ohmura, T. Hara and K. Tsuzaki: J. Mater. Res. 18 (2003) 14651470.

108) T. Ohmura, T. Hara and K. Tsuzaki: Scr. Mater. 49 (2003) 1157-1162.

109) T. Ohmura, A. Minor, E. Stach and J.W. Morris, Jr.: J. Mater. Res. 19 (2004) 3626-3632.

110) L. Wu, L. Liu, J. Liu and R. Zhang: Mater. Trans. 53 (2012) 504-507.

111) T. Ogura, K. Ueda, Y. Saito and A. Hirose: Mater. Trans. 52 (2011) 979-984.

112) J. Li, T. Ohmura and K. Tsuzaki: Mater. Trans. 46 (2005) 1301-1305.

113) J.-H. Kim, T. Tabaru and H. Hirai: Mater. Trans. 44 (2003) 673-676.

114) C.A. Schuh and T.G. Nieh: Acta Mater. 51 (2003) 87-99.

115) C.A. Schuh, A.C. Lund and T.G. Nieh: Acta Mater. 52 (2004) 58795891.

116) D. Pan, A. Inoue, T. Sakurai and M.W. Chen: Proc. Natl. Acad. Sci. 
USA 105 (2008) 14769-14772.

117) Z. Zhang, Y. Wang, Z. Qi, W. Zhang, J. Qin and J. Frenzel: J. Phys. Chem. C 113 (2009) 12629-12636.

118) C.A. Volkert, A. Donohue and F. Spaepen: J. Appl. Phys. 103 (2008) 083539.

119) R. Vaidyanathan, M. Dao, G. Ravichandran and S. Suresh: Acta Mater. 49 (2001) 3781-3789.

120) T. Benameur, K. Hajlaoui, A.R. Yavari, A. Inoue and B. Rezgui Mater. Trans. 43 (2002) 2617-2621.

121) W. Li, B. Wei, T. Zhang, L. Zhang and Y. Dong: Mater. Trans. 46 (2005) 2954-2958.

122) W. Peng, B. Wei, T. Zhang, Y. Liu and L. Li: Mater. Trans. 48 (2007) 1759-1764.

123) Z. Bian, H. Kato and A. Inoue: Mater. Trans. 46 (2005) 798-804.

124) N.A.P.K. Kumar, C. Li, K.J. Leonard, H. Bei and S.J. Zinkle: Acta Mater. 113 (2016) 230-244.

125) D.-H. Lee, M.-Y. Seok, Y. Zhao, I.-C. Choi, J. He, Z. Lu, J.-Y. Suh, U. Ramamurty, M. Kawasaki, T.G. Langdon and J.-I. Jang: Acta Mater 109 (2016) 314-322.

126) A. Bisht, M. Srivastava, R.M. Kumar, I. Lahiri and D. Lahiri: Mater. Sci. Eng. A 695 (2017) 20-28.

127) O. Cedillos-Barraza, S. Grasso, N.A. Nasiri, D.D. Jayaseelan, M.J. Reece and W.E. Lee: J. Eur. Ceram. Soc. 36 (2016) 1539-1548.

128) S. Parvizi, Z. Ahmadi, M.J. Zamharir and M. Shahedi Asl: Int. J. Refract. Met. Hard Mater. 75 (2018) 10-17.

129) B. Mohammadpour, Z. Ahmadi, M. Shokouhimehr and M. Shahedi Asl: Ceram. Int. 45 (2019) 4262-4267.

130) M. Shahedi Asl: Ceram. Int. 43 (2017) 15047-15052.

131) B. Nayebi, Z. Ahmadi, M. Shahedi Asl, S. Parvizi and M. Shokouhimehr: J. Alloy. Compd. 805 (2019) 725-732.

132) A. Sabahi Namini, A. Motallebzadeh, B. Nayebi, M. Shahedi Asl and M. Azadbeh: Mater. Chem. Phys. 223 (2019) 789-796.

133) H. Istgaldi, M. Shahedi Asl, P. Shahi, B. Nayebi and Z. Ahmadi: Ceram. Int. 46 (2020) 2923-2930.

134) G.D. Goh, V. Dikshit, A.P. Nagalingam, G.L. Goh, S. Agarwala, S.L. Sing, J. Wei and W.Y. Yeong: Mater. Des. 137 (2018) 79-89.

135) T. Li, Y. Chen, X. Hu, Y. Li and L. Wang: Mater. Des. 142 (2018) $247-258$.

136) N.E. Uzan, S. Ramati, R. Shneck, N. Frage and O. Yeheskel: Addit Manuf. 21 (2018) 458-464.

137) C. de Formanoir, G. Martin, F. Prima, S.Y.P. Allain, T. Dessolier, F Sun, S. Vivès, B. Hary, Y. Bréchet and S. Godet: Acta Mater. 162 (2019) 149-162.

138) A. Mata, A.J. Fleischman and S. Roy: Biomed. Microdevices 7 (2005) 281-293.

139) J.C. Tan and A.K. Cheetham: Chem. Soc. Rev. 40 (2011) 1059-1080

140) S.F. Wang, L. Shen, Y.J. Tong, L. Chen, I.Y. Phang, P.Q. Lim and T.X. Liu: Polym. Degrad. Stabil. 90 (2005) 123-131.

141) X. Shi, T.A. Nguyen, Z. Suo, Y. Liu and R. Avci: Surf. Coat. Tech. 204 (2009) 237-245.
142) M.R. VanLandingham, J.S. Villarrubia, W.F. Guthrie and G.F. Meyers: Macromol. Symp. 167 (2001) 15-44.

143) V. Domnich, Y. Gogotsi and S. Dub: Appl. Phys. Lett. 76 (2000) 2214-2216.

144) B. Das, K. Eswar Prasad, U. Ramamurty and C.N.R. Rao: Nanotechnology 20 (2009) 125705.

145) S.-L. Gao and E. Mäder: Compos., Part A 33 (2002) 559-576.

146) D. Ciprari, K. Jacob and R. Tannenbaum: Macromolecules 39 (2006) 6565-6573.

147) A. Schneider, G. Francius, R. Obeid, P. Schwinté, J. Hemmerlé, B. Frisch, P. Schaaf, J.-C. Voegel, B. Senger and C. Picart: Langmuir 22 (2006) 1193-1200.

148) H. Lu, B. Wang, J. Ma, G. Huang and H. Viswanathan: Mech. Time Depend. Mater. 7 (2003) 189-207.

149) J.L. Cuy, A.B. Mann, K.J. Livi, M.F. Teaford and T.P. Weihs: Arch Oral Biol. 47 (2002) 281-291.

150) H. Fan, L. Wang, K. Zhao, N. Li, Z. Shi, Z. Ge and Z. Jin: Biomacromolecules 11 (2010) 2345-2351.

151) P. Roschger, E.P. Paschalis, P. Fratzl and K. Klaushofer: Bone 42 (2008) 456-466.

152) D.M. Ebenstein and L.A. Pruitt: Nano Today 1 (2006) 26-33.

153) X. Xin, M. Hussain and J.J. Mao: Biomaterials 28 (2007) 316-325.

154) M.P.E. Wenger, L. Bozec, M.A. Horton and P. Mesquidaz: Biophys. J. 93 (2007) 1255-1263.

155) S. Hengsberger, A. Kulik and Ph. Zysset: Bone 30 (2002) 178-184.

156) G.W. Marshall, Jr., M. Balooch, R.R. Gallagher, S.A. Gansky and S.J. Marshall: J. Biomed. Mater. Res. 54 (2001) 87-95.

157) W.H. Roos, R. Bruinsma and G.J.L. Wuite: Nat. Phys. 6 (2010) 733743.

158) F. Barthelat, C.-M. Li, C. Comi and H.D. Espinosa: J. Mater. Res. 21 (2006) 1977-1986.

159) G. Constantinides and F.-J. Ulm: Cement Concr. Res. 34 (2004) 6780 .

160) X. Li, H. Gao, C.J. Murphy and K.K. Caswell: Nano Lett. 3 (2003) 1495-1498.

161) F. Pacheco-Torgal and S. Jalali: Constr. Build. Mater. 25 (2011) 582590.

162) J.-I. Jang, M.J. Lance, S. Wen, T.Y. Tsui and G.M. Pharr: Acta Mater. 53 (2005) 1759-1770.

163) H.M. Jennings, J.J. Thomas, J.S. Gevrenov, G. Constantinides and F.-J. Ulm: Cement Concr. Res. 37 (2007) 329-336.

164) G. Constantinides, F.-J. Ulm and K. Van Vliet: Mater. Struct. 36 (2003) 191-196.

165) J.A. Zimmerman, C.L. Kelchner, P.A. Klein, J.C. Hamilton and S.M Foiles: Phys. Rev. Lett. 87 (2001) 165507.

166) K. Velez, S. Maximilien, D. Damidot, G. Fantozzi and F. Sorrentino: Cement Concr. Res. 31 (2001) 555-561.

167) Y. Wada, N. Sekido, T. Ohmura and K. Yoshimi: Mater. Trans. 59 (2018) 771-778. 